\title{
Bony Hydatid Disease of Superior Pubic Ramus with Extension into Pelvis and Proximal Thigh
}

\author{
Khan JA, 'Devkota P, ${ }^{1}$ Acharya BM, ${ }^{1}$ Pradhan NMS, ${ }^{1}$ Shreshtha $\mathrm{S}^{1}$ \\ 'Department of Orthopedics, Patan Hospital, Lagankhel, Nepal
}

\section{ABSTRACT}

Hydatid disease is caused by the tapeworm of genus 'Echinococcus. Genus Echinococcus has different species including Echinococcus vogeli, Echinococcus granulosus and Echinococcus multilucularis. Echinococcus granulosus is the most common cause of hydatid disease in humans. This disease can take place either directly through ingestion of parasite eggs from contact with infected dogs or indirectly from the ingestion of contaminated water or food.

Infestation of hydatid disease in humans most commonly occurs in the liver (55-70\%), followed by the lungs (18-35\%). Bone hydatidosis however is very rare, whenever it occurs; it is usually secondary to visceral involvement. We present herein a case of primary hydatid cyst involving superior pubic ramus in a 43 years male patient, which is not a common site for the occurrence of this disease. Diagnosis is usually delayed if high index of suspicion is not there. MRI is a good tool for reaching diagnoses.

Key words: hydatid disease, superior pubic rami, pelvic extension.

\section{INTRODUCTION}

Hydatid disease is endemic in Kathmandu owing improper slaughter houses and availability of stray dogs. ${ }^{1}$ The flatworm Echinococcus granulosus causes the commonest form of hydatid disease. This is usually localized in the liver and the lungs. Although any organ in the body may be involved, primarily muscles are seen to be affected rarely. Musculoskeletal cysts account for $0.7-3 \%$ of total cases of hydatidosis. ${ }^{2,3}$ In the musculoskeletal system, cysts may grow primarily from direct implantation of oncospheres or secondarily from metastatic dissemination of visceral cyst. ${ }^{4}$ Intraosseous lesions usually begin at the epiphysis and may be polycystic or may occur, though less often, in the form of a solitary hydatid cyst. ${ }^{5}$ The polycystic type occurs because the cyst is unable to expand and fragments causing diffuse spreading of the daughter cyst and scolices along the bone canals owing to bone rigidity. In both types of hydatid cyst, pressure absorption of the bone, with resultant thinning and fracturing and extension through the periosteum and soft tissues are known to occur. ${ }^{6}$ Hydatid disease of the bone is often asymptomatic for a long duration and is usually detected after a sudden fracture, secondary infection or neurovascular lesion caused by compression. ${ }^{5-9} \mathrm{~A}$ definite preoperative diagnoses without histological examination is often difficult, as there are not pathogonomonic signs. Radiographic findings, perhaps

\author{
Correspondence: \\ Dr. Javed Ahmad Khan \\ Department of orthopedics \\ Patan Hospital, Lagankhel, Nepal. \\ Phone: +977-9841302553 \\ Email: driaved123@yahoo.com
}


misdiagnosed as those of other lesions and immunologic test, are of limited value. ${ }^{10} \mathrm{MRI}$ especially T1 weighted images are highly sensitive in detection of all the cysts and their relationship. ${ }^{15}$ We herein present a case of hydatid cyst superior pubic rami, which is an uncommon site for occurrence of this disease.

\section{CASE REPORT}

We present the case of 41 years male patient complaining of left groin pain for 6 months duration. Initially it used to occur after walking but for past one month he also complained of night pain in the same region. He had suffered from limping due to painful leg during this period of time. On examination he was of average built. General and systemic examinations were within normal limit. There was tenderness at the left groin region. Left Hip internal rotation was painful. Regional lymph nodes were not enlarged and distal circulation and neurology was normal.

Routine blood count was within normal limit. Serum calcium, Alkaline phosphatase were also normal. Plain $x$-ray pelvis showed destructive lesion involving left superior pubic rami. Ultrasound examination showed at least 3 cysts in infravesical area, superior pubic region and inguinal region, liver was normal. Chest $\mathrm{x}$-ray was also normal. MRI showed multiple cysts in the left suprapubic region, infravesical area and left proximal thigh with probable diagnosis of hydatid cysts. ELISA test was strongly positive for Echinococcus.

Patient was treated with oral Albendazole 400mg twice daily for 4 weeks followed by two weeks interval for six months. Liver function test was regularly monitored. After three months of treatment patient was symptomatically better, and did not have groin pain. Consultations were also done with general and urologic surgeon regarding surgical excision of cysts. Patient was reluctant to surgery so he was being treated conservatively later patient was lost in follow-ups.

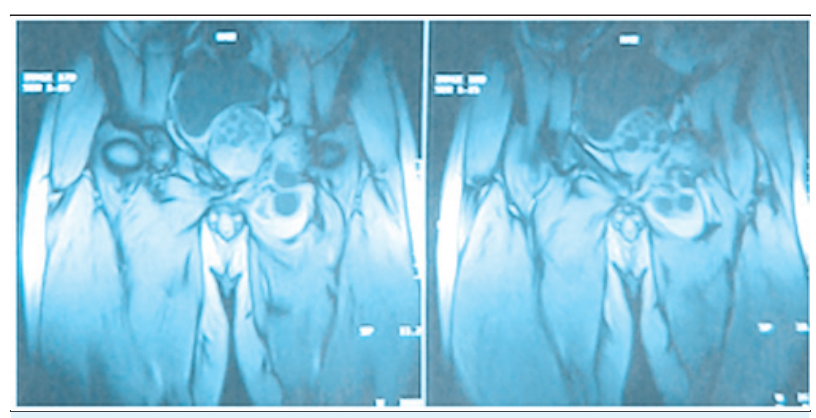

Figure 1. Coronal sections MRI images T1showing primary cyst (small arrow) and secondary cysts (triangles). Multiple daughter cysts in primary cyst (Large arrow).

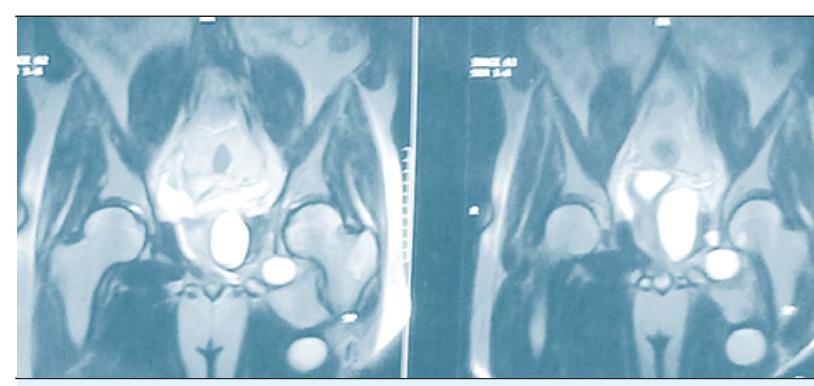

Figure 2. Coronal sections MRI images T2 multiple cysts(arrows).

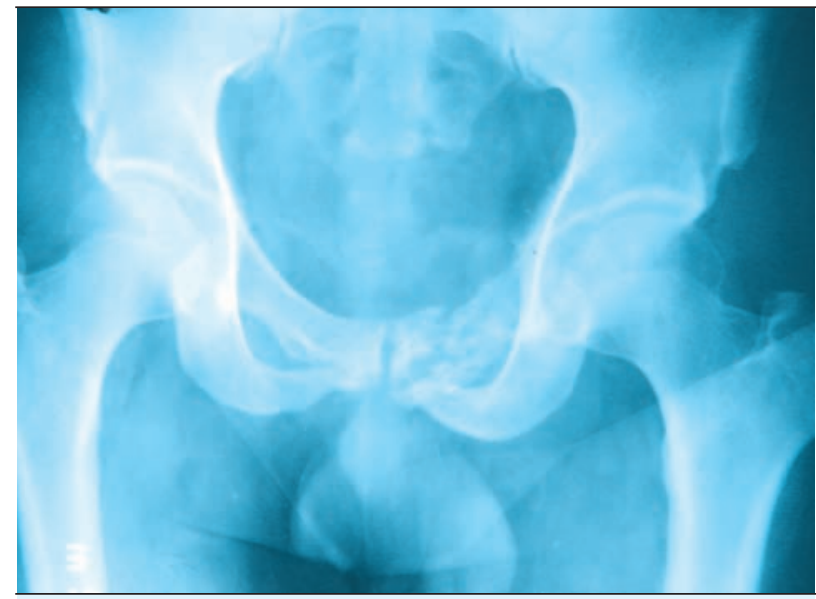

Figure 3. X-ray AP view pelvis showing lytic lesion of superior pubic ramus and body of pubis (arrows).

\section{DISCUSSION}

The disease in the bone and joint begins once the blood borne scolex settles there. It is a very slow process and therefore, bone cysts are seldom discovered in childhood,

Even though infestation probably occurs at this time. ${ }^{11}$ The bone offers mechanical resistance. Due to pressure, the trabeculae are absorbed and if the cortex is breached, the cyst expands uniformly in the soft tissues. There is fragmentation and conglomeration of the daughter cyst. ${ }^{12,13}$ Disease should be suspected in cystic lesions affecting

the bone, especially in endemic areas, as it may easily be misdiagnosed. It can mimic tuberculosis, simple bone cyst, sub-acute osteomylitis, giant cell tumors, malignant fibrous histiocytoma, myeloma and chondrosarcoma. ${ }^{14}$ the diagnosis of osseous hydatidosis is still primarily based on roentgeno-graphic findings. Sometimes, however, the diagnosis is established only after surgery. ${ }^{16} \mathrm{MRI}$ especially $\mathrm{T} 1$ weighted images are highly sensitive in detection of all the cysts and their relationship. ${ }^{15}$ Treatment of osseous hydatidosis is closer 
Khan et al. Bony Hydatid Disease of Superior Public Ramus with Extension into Pelvis and Proximal Thigh

to oncologic therapy than to the usual surgical treatment of visceral hydatid cysts. Because of the poor results with medical treatment, osseous hydatidosis must be treated by a radical operation with wide excision. In the main, the prognosis of osseous hydatidosis remains poor, especially with spinal and pelvic localizations, which are the most frequent ones. The prognosis and treatment of osseous hydatidosis belong in the same category as a locally malignant lesion. ${ }^{16}$

In conclusion, the preoperative differential diagnosis of skeletal cystic and lytic lesions should include cystic echinococcosis, since the diagnosis may easily be missed, unless be kept in mind.

\section{REFERENCES}

1. Waltner-Toews D,Neudoerffer C, Joshi DD,Tamang MS. Agro-urban Ecosystem Health Assessment in Kathmandu, Nepal: Epidemiology, Systems, Narratives. EcoHealth 2005;2:155-64

2. Kumar S, Jha RR, Sinha BC, Jha B. Primary hydatid cyst in the right temporal region of the head. Indian J Surg 1986;48:357-8.

3. Tatari H, Baran O, Sanlidag T, Gore O, Ak D, Manisali M, et al . Primary intramuscular hydatidosis of supraspinatus muscle. Arch Orthop Trauma Surg 2001;121:93-4.

4. Singh CM. Hydatid cyst of adductor longus. J Indian Med Assoc 1990;88:288.

5. Pintilie DC, Panoza G, Hatmanu D, Fahrer M. Echinococcosis of the humerus. Treatment by resection and bone-grafting: A case report. J Bone Joint Surg Am 1966;48:957-61.

6. Morris DL. Musculoskeletal hydatid disease. Coombs R, Fitztgerald RH Jr, editors. Infections in the orthopaedic patients. Butter Worth and Co Ltd.: London; 1989. p. 314-22.

7. Karray S, Zlitni M, Fowels JV, Zouari O, Slimane N, Kassab MT, et al . Vertebral hydatidosis and paraplegia. J Bone Joint Surg Br 1990;72:84-8.

8. Knudsen C, Marks R, Learmonth GM. Orthopaedic hydatid disease. J Bone Joint Surg 1988;70:504.
9. Ferrandez HD, Gomez-Castresana F, Lopez-Duran L, Mata P, Brandau D, Sanchez-Barba A. Osseous hydatidosis. J Bone Joint Surg Am 1978;60:685-90.

10. Barrett NR, Thomas D. Pulmonary hydatid disease. Br J Surg 1952;40:222-44.

11. Kumar R, Cornah MS, Morris DL. Hydatid cyst: A rare cause of a pathological fracture: A case report. Injury 1984;15:2845.

12. Alldred AJ, Nisbet NW. Hydatid disease of bone in Australia. J Bone Joint Surg Br 1964;46:260-7.

13. Saidi F. Surgery of Hydatid disease: Hydatid cyst of bone. London: WBSaunders;1976. p. 338-51.

14. Booz MK. Hydatid disease of bone in Kuwait with special reference to differential diagnosis. J Kuwait Med Assoc $1968 ; 2: 27$.

15. Fahl $\mathrm{M}$ et al. Magnetic resonance imaging in intrdural and extradural echinococcosis. Clinical imaging 1994;18:179-183.

16. Zlitni M, Ezzaouia K, Lebib H, Karray M, Kooli M, Mestiri M. Hydatid cyst of bone: diagnosis and treatment. World J Surg 2001 Jan;25(1):75-82. 